\title{
Modulation of adhesive properties of DEAE-dextran with laminin
}

\author{
James Varani, ${ }^{1, *}$ Suzanne E. G. Fligiel, ${ }^{2}$ Dennis R. Inman, ${ }^{2}$ Ted F. Beals, ${ }^{3}$ and William J. Hillegas ${ }^{4}$ \\ ${ }^{1}$ Department of Pathology, University of Michigan, Ann Arbor, Michigan 48109; ${ }^{2}$ Department of Pathology, \\ VAMC-Wayne State University, Allen Park, Michigan 48101; ${ }^{3}$ Department of Pathology, WAMC-University of \\ Michigan, Ann Arbor, Michigan 48109; ${ }^{4}$ Solohill Labs, Inc., Ann Arbor, Michigan 48104
}

Human squamous epithelial cells produce lower amounts of laminin and fibronectin when cultured on DEAE-dextran than when cultured on gelatin-coated polystyrene (Biotechnol. Bioeng., 33:1235). The epithelial cells also spread much more slowly on DEAE-dextran than they do on gelatincoated polystyrene. To determine if the low level of matrix production by cells grown on DEAE-dextran contributed to the slowness of cell spreading on this substrate, microcarriers made from DEAE-dextran were treated with exogenous laminin $\left(10 \mu \mathrm{g} / \mathrm{cm}^{2}\right.$ of surface area) and then examined for ability to support cell adhesion. Squamous epithelial cells spread as rapidly on the laminin-treated
DEAE-dextran as they did on gelatin-coated polystyrene (much more rapidly than on untreated DEAE-dextran). This indicates 1) that laminin can bind to DEAE-dextran in a fashion that is biologically usable by anchorage-dependent cells, and 2) that when laminin is bound to DEAEdextran, the failure of squamous epithelial cells to rapidly spread is overcome. These data support the hypothesis that failure of the cells to synthesize an intact extracellular matrix on DEAE-dextran is responsible, at least in part, for the slowness with which cells spread on this substrate. (c) 1995 John Wiley \& Sons, Inc.

\section{INTRODUCTION}

Microcarriers are increasingly being utilized for the large-scale cultivation of anchorage-dependent cells. Although several different materials have proven useful as microcarrier substrates, ${ }^{1-5}$ the material originally used as a microcarrier-i.e., DEAE-dextran ${ }^{1}$ is still the most widely utilized in industrial operations. Cells rapidly attach to the positively charged DEAE groups on the crosslinked dextran. However, spreading on this surface occurs more slowly than on other surfaces which are used in microcarrier form. ${ }^{6,7}$ The reason for this is unknown. However, we showed in a recent study that synthesis and secretion of laminin and fibronectin were lower when human fibroblasts and epithelial cells were cultured on DEAE-dextran microcarriers than when the same cells were grown on several other substrates. ${ }^{8}$ Subsequently, we showed that matrix production was retarded on other cationic substrates as well ${ }^{9}$ and similar observations were made by other investigators. ${ }^{10}$ Like DEAE-dextran, the other cationic substrates that

*To whom correspondence should be addressed. did not support matrix production also failed to support rapid cell spreading. ${ }^{9}$ Since both laminin and fibronectin are potent cell adhesion factors, ${ }^{11,12}$ we speculated that the failure to produce an intact matrix may underlie, at least in part, the abnormal adhesive characteristics seen on substrates such as DEAEdextran. In order to test this possibility directly, we have in the present study prepared laminin-coated DEAE-dextran microcarriers and compared cell attachment and spreading on this substrate with results obtained on untreated DEAE-dextran.

\section{MATERIALS AND METHODS}

\section{Cells}

A human squamous epithelial cell line, designated as UM-SCC-1, was used in these studies. The UMSCC -1 cells were derived originally from a tumor in the floor of the mouth. The cells were provided to us as a gift by Dr. Thomas E. Carey (Department of Oto- 
laryngology, University of Michigan). Although transformed, our recent studies have shown that these cells grow as contact-inhibited cells with the cobblestone appearance of normal, undifferentiated keratinocytes. Further, the UM-SCC- 1 cells are capable of undergoing differentiation in response to agents that induce differentiation in normal keratinocytes. ${ }^{13,14}$ In the present study, the cells were grown at $37^{\circ} \mathrm{C}$ and $5 \% \mathrm{CO}_{2}$. Growth medium was Minimal Essential Medium of Eagle with Earle's salts (MEM) supplemented with 10\% fetal bovine serum, nonessential amino acids, $100 \mathrm{U} / \mathrm{mL}$ penicillin and $100 \mu \mathrm{g} / \mathrm{mL}$ streptomycin. The cells were subcultured by trypsinization as required.

\section{Preparation of laminin-treated DEAE-dextran}

Microcarriers made from DEAE-dextran (Cytodex I, Pharmacia, Piscataway, NJ) and gelatin-coated polystyrene (Solohill Labs, Ann Arbor, MI) were used as substrates in this study. Laminin was obtained from Collaborative Research (Boston, MA). To obtain laminin bound to the DEAE-dextran substrate, the DEAE-dextran microcarriers were first hydrated as recommended by the manufacturer. We then added the laminin to the microcarrier beads at a final concentration of $10 \mu \mathrm{g} / \mathrm{cm}^{2}$ in phosphate-buffered saline (PBS). The laminin and substrate were incubated at $4^{\circ} \mathrm{C}$ for 2 days with gentle mixing. The microcarriers were then washed two times to remove nonbound laminin and were ready to use. DEAE-dextran microcarriers not exposed to laminin were treated in an identical way for use as a control. The gelatin- coated polystyrene microcarriers were prepared according to their manufacturer's recommendation.

\section{Measurement of adhesion}

Cells were harvested from monolayer culture and examined for attachment and spreading on gelatincoated polystyrene microcarriers and on untreated and laminin-treated DEAE-dextran microcarriers. Cells were added to the substrates in MEM containing 10\% fetal bovine serum. The assays were carried out in $35-\mathrm{mm}$ (diameter) bacteriological dishes that had been pretreated for $2 \mathrm{~h}$ with a $10 \mathrm{mg} / \mathrm{mL}$ solution of bovine serum albumin in PBS ( $2 \mathrm{~mL} / \mathrm{dish})$ to prevent cell attachment to the plastic dish. Enough substrate was added to each dish to provide approximately $30 \mathrm{~cm}^{2}$ of surface area. Cells were added at a concentration of $5 \times 10^{5}$ cells/dish. The cells and microcarriers were mixed by gently swirling the dishes at $15 \mathrm{~min}$ intervals over the first hour and at half hour intervals over the next three hours. Cell attachment and spreading were measured at various times in the following manner: First, glutaraldehyde was added to the dishes to bring the final concentration to $2 \%$. The microcarriers with attached cells were then removed from the dish and examined under phasecontrast microscopy to determine the number of cells on the beads and the percentage of bound cells that were spread. In addition, samples from the various dishes were processed for scanning electron microscopy (SEM) and examined using an ISI Super 3A scanning electron microscope. The exact methods for processing and examining the specimens have been described previously. ${ }^{3}$

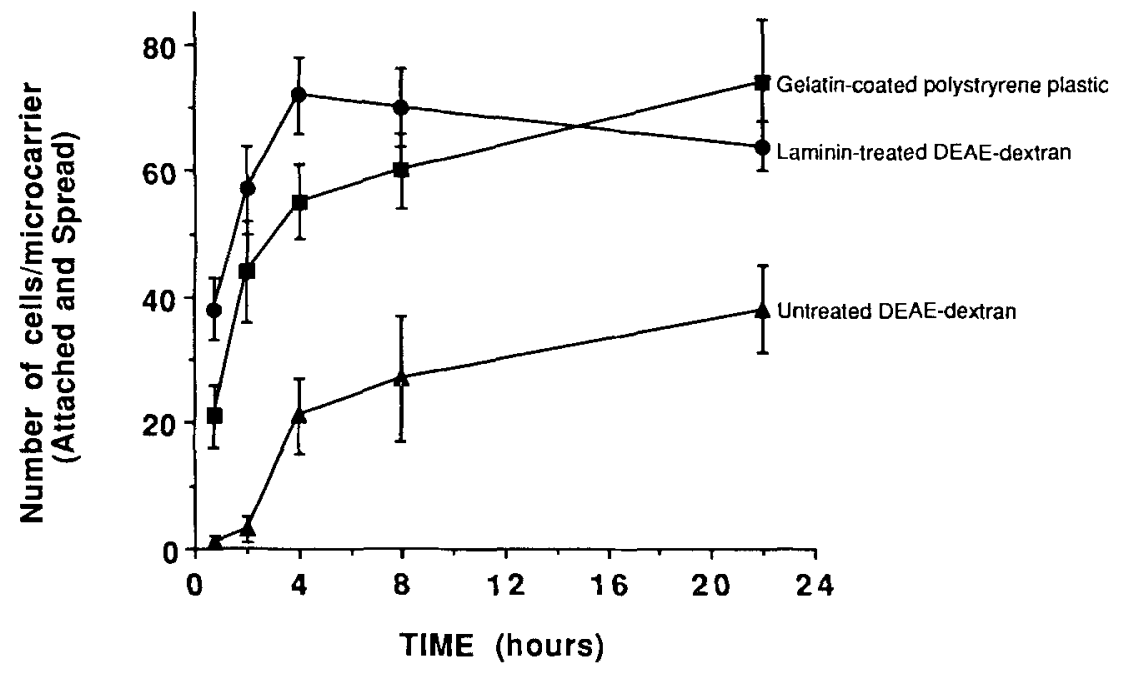

Figure 1. Attachment and spreading of UM-SCC-1 cells on untreated DEAE-dextran, laminin-treated DEAE-dextran, and gelatin-coated polystyrene. The adhesion assay was carried out as described in Materials and Methods utilizing MEM supplemented with $10 \%$ fetal bovine serum as culture medium. Values shown represent the number of cells attached and spread \pm standard deviations based on four samples per data point. The experiment was repeated three times with similar results. 


\section{RESULTS}

\section{Attachment and spreading of UM-SCC-1 cells on untreated and laminin-treated DEAE-dextran}

Experiments were carried out in the present study to determine if laminin bound to DEAE-dextran microcarriers would support cell attachment and spreading as it does when bound to other materials such as polystyrene. DEAE-dextran microcarriers were treated with laminin $\left(10 \mu \mathrm{g} / \mathrm{cm}^{2}\right.$ of surface area) as described in the Materials and Methods section. The laminin-treated DEAE-dextran microcarriers were then compared to untreated DEAE-dextran microcarriers and gelatin-coated polystyrene microcarri- ers for ability to support attachment and spreading of UM-SCC-1 cells. Cells attached rapidly to untreated DEAE-dextran but, as expected, spreading was slow on this substrate relative to the rate of spreading on gelatin coated polystyrene. In contrast, UM-SCC-1 cells attached and spread rapidly on laminin-treated DEAE-dextran. Quantitative data from this experiment are shown in Figure 1.

Figure 2 shows scanning electron micrographs of UM-SCC- 1 cells on the same three substrates $2 \mathrm{~h}$ after plating. The differences between cells on untreated and laminin-treated DEAE-dextran are readily apparent. Interestingly, it can be seen from this figure that although the cells rapidly spread on laminin-coated DEAE-dextran, the appearance of the spread cells is different from the appearance of the same cells
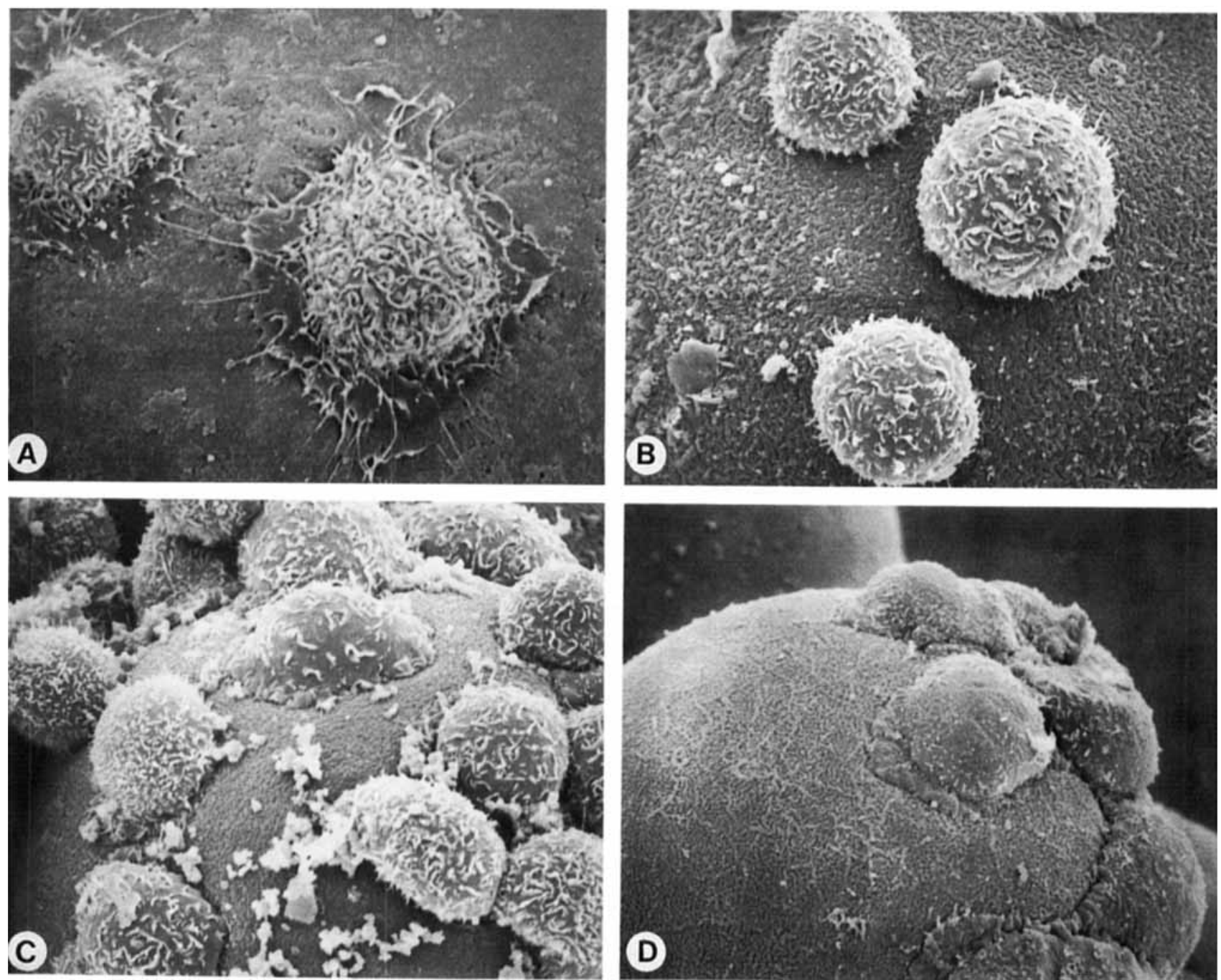

attacnment to untreated UEAE-dextran (B) but do after attachment to laminin-coated DEAE-dextran (C). Photographs for both (B) and (C) were obtained $2 \mathrm{~h}$ after addition of cells to the substrate. Although UM-SCC-1 cells do not rapidly spread on untreated DEAE-dextran, they do so after longer time periods (D). This photograph was obtained $18 \mathrm{~h}$ after plating of the cells. (Magnification: $(A) \times 2300$, (B) $\times 2800$, (C) $\times 2200$, and (D) $\times 1800$.) 
spread on gelatin-coated polystyrene. The appearance of cells on laminin-treated DEAE-dextran $2 \mathrm{~h}$ after plating resembles the appearance of cells on untreated DEAE-dextran after longer periods of time (18 h). Thus, the addition of exogenous laminin to DEAE-dextran increases the rate of spreading on this substrate.

\section{DISCUSSION}

Recent studies have shown that production of extracellular matrix molecules can be significantly retarded when the cells are grown on charged surfaces. ${ }^{8-10}$ It was found, for example, that human diploid fibroblasts and human squamous epithelial cells produced smaller amounts of laminin $(85-90 \%$ reduction) and fibronectin (30-50\% reduction) when they were grown on DEAE-dextran microcarriers than when the same cells were grown on a number of different substrates. ${ }^{8}$ We have speculated that the failure to produce an intact matrix could account for the slowness with which cells spread on DEAEdextran. To obtain direct evidence for this, we prepared DEAE-dextran microcarriers coated with laminin from an exogenous source and then examined the interaction of human squamous epithelial cells with this modified substrate. The data from these experiments demonstrated 1) that laminin could be bound to DEAE-dextran in a biologically usable form, and 2) that when DEAE-dextran was treated with exogenous laminin, the cells attached and spread as readily on this substrate as they did on gelatin-coated polystyrene.

Taken together, these observations suggest that failure of cells to produce an extracellular matrix on substrates such as DEAE-dextran does, in fact, underlie the retardation of spreading that is observed on these substrates. From a practical standpoint, the data suggest that it might be possible to overcome this property of charged substrates by "building" a relevant matrix component into the charged surface. While intact matrix molecules such as laminin and fibronectin are not likely to be the factors of choice for a number of reasons, synthetic peptides are available which maintain the adhesion-promoting properties of their parent molecules. ${ }^{15}$ Such peptides might be useful not only for providing the impetus for rapid cell attachment and spreading, but might also provide a measure of specificity.

A final question relates to the possible mechanisms accounting for retardation of matrix synthesis on charged surfaces. While we do not have a definitive answer to this question, it has been shown in the past that the same substrates which do not support matrix production promote a high level of proteolytic en- zyme (plasminogen activator) secretion. ${ }^{16,17}$ These enzymes are potent matrix degraders and it seems reasonable to suggest that the low level of matrix production might reflect enhanced degradation. Additional studies will be needed to definitively show what role enhanced proteolysis plays in this process. Regardless of mechanism, it is apparent that matrix production by anchorage-dependent cells is significantly influenced by the substrate on which the cells are cultured. Our knowledge of the molecular events that underlie this phenomenon will help us design substrates that are optimal for in vitro cell growth.

This study was supported in part by grant CA58154 from the USPHS.

\section{References}

1. A. L. van Wezel, "Growth of cell strains and primary cells on microcarriers," Nature, 216, 65-66 (1967).

2. V. Nielson and I. Johansson, "Biosilon: Optimal culture conditions and various research scale culture techniques," Dev. Biol. Standard, 46, 131-136 (1980).

3. J. Varani, M. Dame, T. F. Beals, and J. A. Wass, "Growth of three established cell lines on glass microcarriers," Biotechnol. Bioeng., 25, 1359-1372 (1983).

4. C. Gebb, J. M. Clark, M. D. Hirtenstein, G. Lindgren, U. Lindskog, B. Lindgren, and P. Vretblad, "Alternative surfaces for microcarrier culture of animal cells," Dev. Biol. Stand., 50, 93-102 (1982).

5. C. Kesse and I. Giaever, "Cell growth on liquid microcarriers," Science, 219, 1448-1449 (1983).

6. J. Varani, M. J. Bendelow, J. H. Chun, and W. J. Hillegas, "Cell growth on microcarriers: Comparison of proliferation and recovery from various substrates," J. Biol. Stand. 14, 331-336 (1986).

7. J. Varani, M. Dame, J. Rediske, and W. J. Hillegas, "Substrate-dependent differences in growth and biological properties of fibroblasts and epithelial cells grown in microcarrier culture," J. Biol. Stand., 13, 67 76 (1985).

8. J. Varani, S. E. G. Fligel, D. R. Inman, D. L. Helmreich, M. J. Bendelow, and W. Hillegas, "Substratedependent differences in production of extracellular matrix molecules by squamous carcinoma cells and diploid fibroblasts," Biotechnol. Bioeng., 33, 1235-1241 (1989).

9. J. Varani, D. R. Inman, S. E. G. Fligiel, and W. J. Hillegas, "Use of recombinant and synthetic peptides as attachment factors for cells on microcarriers," $\mathrm{Cy}$ totechnology, 13, 89-98 (1993).

10. J. R. Cook and R. G. Van Buskirk, "Matrix and laminin synthesis in MDCK cells in vitro," In Vitro Cell. Dev. Biol., 30A, 733-735 (1994).

11. J. R. Couchman, M. Hook, D. A. Rees, and R. Timpl, "Adhesion, growth, and matrix production by fibroblasts on laminin substrates, J. Cell Biol., 96, 177-183 (1983).

12. V. P. Terranova, D. Rohrbach, and G. R. Martin, "Role of laminin in the attachment of PAM 212 (epithelial) cells to basement membrane collagen," Cell, 22, 719-726 (1980).

13. L. Schuger, V. M. Dixit, T. E. Carey, and J. Varani, 
"Modulation of squamous carcinoma cell growth, morphology, adhesiveness and extracellular matrix production by interferon- $\gamma$ and tumor necrosis factor$\alpha, "$ Pathology, 58, 279-286 (1990).

14. J. Varani, D. F. Gibbs, D. R. Inman, B. Shah, S. E. G. Fligiel, and J. J. Voorhees, "Inhibition of epithelial cell adhesion by retinoic acid: relationship to reduced extracellular matrix production and alterations in $\mathrm{Ca}^{2+}$ levels," Am. J. Pathol., 138, 887-895 (1991).

15. E. Ruoslahti and M. D. Pierschbacher, "Arg-Gly-Asp: A versatile cell recognition signal," Cell, 44, 517-518 (1986).
16. J. Varani, J. D. Hasday, R. G. Sitrin, P. G. Brubaker, and W. J. Hillegas, "Proteolytic enzymes produced by MRC -5 cells on various substrates," In Vitro Cell. Dev. Biol., 22, 575-582 (1986).

17. J. Varani, R. G. Sitrin, and W. Hillegas, "Expression of plasminogen activator and plasminogen activator inhibitor mRNA in human fibroblasts grown on different substrates," Cytotechnology, 9, 157-162 (1992).

Received December 28, 1992

Accepted February 22, 1995 